\title{
The Researcher Librarian Partnership: building a culture of research
}

\author{
Helen Partridge, Insa Haidn, Terry Weech, Lynn Silipigni Connaway and \\ Michael Seadle
}

\begin{abstract}
Increasingly, the library and information science (LIS) practitioner is being challenged to incorporate research into the context of their professional work. This paper reports on the Researcher-Librarian Partnership, a research-mentoring programme that was initiated by the International Federation of Library Associations and Institutions. Six new LIS practitioners within their first seven years of professional practice took part in the programme. Each was partnered with an experienced LIS researcher who provided mentoring and support. During the 12-month programme the new professionals designed and implemented a research project on a topic of interest. This paper outlines the details of the programme providing observations on how research mentoring can be a powerful
\end{abstract}

\section{Authors}

Helen Partridge is Professor in the School of Information Systems at Queensland University of Technology in Australia. She is co-leader of the Information Studies Group and her research focuses on the interplay between information, learning and technology, she specializes in qualitative research.

Email: h.partridge@qut.edu.au

Insa Haidn is a Library Adviser at QUT Library and has worked in several academic libraries in Australia over the past nine years, including reference, information services, lending and collection access.

Terry Weech was Chair of the IFLA Library Theory and Research Standing Committee from 2009 - 2013. He is an Associate Professor at the Graduate School of Library and Information Science at the University of Illinois in UrbanaChampaign, USA. His research areas include International Library Education and Assessment and Evaluation of Library Services.

Lynn Silipigni Connaway is Senior Research Scientist at OCLC Research. She was Chair of Excellence 2013-2014 at Universidad Carlos III de Madrid and leads the user behavior and synthesis activity area at OCLC Research. Her research focuses on user-centered data collection techniques for assessment and evaluation.

Michael Seadle is director of the Berlin School for Library and Information Science, dean of the Faculty of Arts I at Humboldt-Universitätzu Berlin, and chair of the international iSchool Caucus.

Received 07 March 2014

Accepted 04 August 2014 
way to ensure all stakeholders - practitioners, educators and professional associations - can plan an active role in supporting the development of a research culture within the profession.

\section{Introduction}

An on-going criticism of the library and information science (LIS) profession is the lack of rigorous research (see Powell, Baker and Mika, 2002). In today's everchanging information rich and technologically driven world it has become more important than ever that library professionals embrace a culture of research and scholarly enquiry. The current economic environment also requires librarians to assess and evaluate their services to articulate the value of libraries to the community and funding agencies. This is necessary to compete for limited external and internal resources. Librarians must be capable of assessing services and systems based on how and why their clients and communities use them, why they do not use them, and why they choose other services instead; yet, LIS education and training are not offering sufficient courses in user-centred assessment and evaluation (Connaway, 2014).

Research skill and knowledge are the essential tool kit for ensuring that libraries and librarians continue to effectively and efficiently meet the evolving needs of the clients and communities they serve. Research must be promoted as a valuable activity for all library professionals. There is an obligation on the part of library educators, employers and professional associations to ensure that practitioners have the necessary skill and knowledge to conduct research effectively. As the international body for the library sector, the International Federation of Library Associations and Institutions (IFLA) has a vital role to play in leading the research charge in the profession. This paper reports on a research-mentoring programme that was implemented by the IFLA Library Theory and Research Section. A research-mentoring programme provides the opportunity for a library research culture to develop among those who are new to the profession. It provides encouragement, assistance and expertise in the research process for the new professionals or protégés taking part. It also enables the more experienced professionals or mentors to acquire leadership skills and to become proactive in their profession. A research-mentoring programme will help to ease the transition from the practice-orientated librarian to the research-orientated librarian. This paper begins by first exploring the key literature relevant to the role of research in the professional practice of LIS professionals and how mentoring can be a powerful tool through which to engender a culture of research in a profession. The paper will then outline the mentoring programme that influenced the recommendations for the future potential offerings of the programme.

\section{Literature review}

\subsection{Research and LIS professionals}

The value of research in the LIS profession has been well-discussed within the literature. In 2001 the Centre for Information Research was commissioned by the Chartered Institute of Library and Information Professionals (CILIP) to conduct 
an investigation into the research landscape for library and information science (LIS). This concluded that the value of research in the LIS discipline could be experienced on both the professional and personal levels. At the professional level, research can inform practice, assist in the future planning of the profession, and raise the profile of the discipline, and the library and information service. At the personal level, research can "broaden horizons and offer individuals development opportunities" (McNicol and Nankivell, 2001, 77). A similar sentiment was voiced by Powell, Baker and Mika (2002) when they stated:

research by LIS practitioners is needed to create new knowledge and thereby contribute to the growth of LIS as a profession or discipline.

(Powell, Baker and Mika, 2002)

They noted the benefits of research as contributing to: the improvement of decision making, problem solving, critical and analytical thinking; the development of more critical consumers of the research literature and librarians who are better equipped to provide user-centred information services; the opportunity for career advancement; and the enhancement of staff morale and librarians' stature.

Juznic and Urbanija (2003) take the discussion one step further by arguing that:

If research is absent, non existent or even scarce, there is no profession, but only an occupation grounded in techniques, routine and common sense.

Similarly, Harvey (2002, xiii) argued that "research and professional practice are inextricably linked" and as such "research skills are a prerequisite [italics added] for those who want to work successfully in information environments". He postulates that research skills are an "essential set of tools which enable information workers to become information professionals" (Harvey, 2002, xiii). According to Harvey (2002):

The work of information professionals is being transformed. The information services we offer, the information products we develop and sell, the information systems we design and implement, are undergoing rapid change. So, too, is the society in which we operate. We have a continual need to determine what is happening, how it is changing, how it will affect our places of work, how it will alter the services we offer. Change and its ramifications is the most important reason why research is necessary, and why it is here to stay. If you don't know something about the tools of research and about how to use these tools, then you cannot be an effective information professional.

(Harvey, 2002, xii)

The challenges for undertaking research also have been well-articulated in the LIS literature. Funding, time, experience, support and access to research have all been 
noted as obstacles to LIS professionals conducting research (Koufogiannakis and Crumley, 2006; Berg, Jacobs and Cornwell, 2013). Inadequate funding has been identified as one of the major obstacles preventing LIS professionals conducting research. LIS professionals lack the range of opportunities to obtain funds to contribute to the implementation of research projects. When funding is available it is often small and does not fully cover the actual costs of undertaking the research. In addition, practitioners may not be comfortable with conducting research and consequently "experience", or lack of it, can also be a major obstacle for librarians undertaking research projects. Many LIS professionals did not receive research training in their formal LIS studies or received only limited training, and access to the opportunity to gain practical research experience in their work environment is not readily available. Koufogiannakis and Crumley (2006) note:

Without keen interest and motivation, research is easily left on the bottom of the priority list and without adequate knowledge of research methods and a lack of experience, it can be difficult to even know where to start.

(Koufogiannakis and Crumley, 2006, 334)

Some LIS professionals lack access to peer reviewed journals and databases. Not being able to regularly read the current literature will limit the extent to which LIS professionals are exposed to new ideas and are able to develop an awareness of the research process. Many librarians have neither the time in their workday to conduct research nor the support of their employer to undertake research during work time (Berg, Jacobs and Dayna, 2013). As noted by Koufogiannakis and Crumley (2006):

without a supportive employer who allows work time to be developed to professional development including research it is challenging to incorporate research into daily practice.

(Koufogiannakis and Crumley, 2006, 334)

The LIS community must find ways to stimulate greater interest and respect for research (McNicol and Nankivell, 2001) and must find ways to overcome the obstacles that keep practitioners from conducting research (Koufogiannakis and Crumley, 2006, 337). The 2001 study of LIS research by CILIP concluded that for this to occur, there must be an:

obligation on the part of library schools, employers and professional bodies to ensure the practitioners have the necessary skills to be able to conduct research effectively.

(McNicol and Nankivell, 2001, 82)

Hallam and Partridge (2006) also observed that the biggest challenge to having the LIS profession engage in research was to encourage stakeholders - educators, individual professionals, employers and the professional associations - to play a 
role in working collaboratively to develop a research culture that should pervade the profession. This paper aims to contribute to meeting the challenge, by describing a formal LIS research-mentoring programme that was initiated by a professional association and which involved the support of LIS educators and LIS professionals.

\subsection{The role of research mentoring}

Mentoring relationships and their benefits have long been discussed in the human resources field, and more recently in the LIS arena. According to Holmes, Hodgson, Simari and Nishimura (2010), the mentoring relationship can be described as:

a series of complex interactions between 2 individuals who have as their primary purpose the growth of the mentee, although this process often results in the professional growth of both parties.

(Holmes, Hodgson, Simari and Nishimura, 2010, 336)

Kram (1985) defines a mentor as a person with more experience and knowledge than the protégé / mentee, who is committed to providing career guidance and advice to allow the protégé to enhance career prospects.

Much has been written about the favourable personal, social and career outcomes of participating in a mentoring relationship. For example, an exhaustive metaanalysis of mentoring relationship research from 1985 to 2006 found that mentoring was significantly related to a myriad of positive outcomes, including behaviours, attitudes, health, interpersonal relationships, motivations, and careers (Eby, Allen, Evans, Ng and DuBois, 2008). Protégés are more likely to display increased levels of satisfaction in their work and higher job performance than those without mentors (Lumpkin, 2011).

One way that mentoring may enact its benefits is through socialisation and networking. According to Holmes et al. (2010) mentoring should assist the development of personal learning networks. The authors describe these networks as lifelong resources for continued career progression and personal and professional growth. Lumpkin (2011) echoes this sentiment, and argues that mentors can facilitate networking for their protégés. As such, mentoring may be particularly useful for individuals new to a job or profession, who have not had the time or experience to build professional networks.

Gibb (1999) reported that participation in a mentoring relationship was found to improve performance, provide support and improve the socialisation of new professionals. The mentoring relationship also has the potential to provide an enriching and supportive environment to new LIS professionals (Freedman, 2009). For example, Hallam and Newton-Smith (2006) described a mentoring programme that aimed to help LIS students transition to their first professional position. The mentoring programme intended to support the students' learning needs and socialise them into the LIS profession. The authors found that protégés 
reported improved job application skills, stronger professional networks and developed stronger career plans after participating in the programme.

At its root, mentoring allows the transferral of relevant knowledge from the mentor to the protégé (Freedman, 2009; Holmes et al., 2010). Indeed, mentors have been described as "role models" (Kostovich, Saban and Collins, 2010) and "advisors" (Farmer, Stockham and Trussell, 2009), highlighting that protégés witness and learn from the behaviours and attitudes displayed by their mentors.

However, the benefits of the mentoring relationship do not seem to be limited to the protégé; the relationship provides benefits to both parties. This includes the benefits of having a "role model", as Hallam and Newton-Smith (2006) found. The authors reported that protégés, as expected, appreciated having a professional role model in the form of their mentor and that they learned from their mentor's personal experience. Likewise, mentors reported that they also benefited from learning from their protégé's personal experience. It appears that mentoring is a two-way street, with gains for both parties. Freedman (2009) argues that mentors gain a personal satisfaction from helping the less-experienced individual and renew their enthusiasm and commitment to their profession. Additionally, Hallam and Newton-Smith (2006) reported that mentors felt an increased level of job satisfaction. It has also been suggested that mentoring programmes highlight the importance of lifelong learning for both mentors and protégés (Hallam and Newton-Smith, 2006).

Farmer, Stockham, and Trussell (2009) describe a formalised mentoring programme at the Kansas State Libraries that had been in place for over 20 years. The main aim of the programme was to guide junior (pre-tenured) librarians through the promotion and tenure process at the University Library. The authors concluded that this mentoring programme met the needs of the new employees and effectively imparted salient information and advice in a coordinated, on-going process. Mentors self-reported to have acted as advisors, advocates and resources to the protégés. Moreover, protégés described their mentors as accessible, approachable, supportive, offering constructive criticism and acting with professional integrity.

An important aspect of professional development, promotion and tenure (where applicable) in the LIS field is conducting research. Research skills and methods can work to ensure that the LIS profession remains current and relevant during changing times (Thorpe, Partridge and Edwards, 2008). As noted earlier there are many obstacles that prevent practising librarians from engaging in research (Koufogiannakis and Crumley, 2006); lack of experience has emerged as one of the more important obstacles to be addressed. Koufogiannakis and Crumley (2006) suggest that many practising librarians are not comfortable conducting research as they have not received the necessary training during their education and may not have had the opportunity for practical research experience in their work environment. 
Recent research has highlighted the benefits of research mentoring to increasing research confidence, experience and output, particularly in the health and medicine fields. For example, authors have asserted that mentoring is fundamentally important in academic medical research (Bettmann, 2009; Blixen, Papp, Hull Rudick and Bramstedt, 2007; Keyser et al., 2008; Kostovich, Saban and Collins, 2010). Moreover, Lumpkin (2009) has suggested that researchmentoring programmes also help to ease the transition of University faculty into new roles.

The mentor-protégé research process enacted through formal research mentoring generally includes both direct communication about relevant research issues, as well as indirect observation of the mentor's behaviour and practice over a period of time (Keyser et al., 2008). Thus, the protégé is able to ask questions regarding the research process, check his / her personal understanding and model appropriate research behaviours. For the LIS professional this would be a valuable opportunity to experience the research process, possibly for the first time.

Kostovich, Saban and Collins (2010) state that the most important function of the research mentor is that of a teacher. Although new professionals may have learnt the theories behind qualitative and quantitative research design, they still need to learn the practicalities and skills involved in actually conducting research. The research mentor acts as both a consultant and advisor and:

can provide the knowledge learned from personal experience, since the research mentor has been down this road at an earlier time.

(Kostovich, Saban and Collins, 2010, 283)

Thus, the mentor's ability to act as a "role model" once again can provide the protégé with the opportunity to witness and learn from the behaviours and attitudes displayed by their mentors. By being exposed to a more experienced researcher, the protégé can hone individual research skills and confidence, which is of particular importance in the LIS field, as new professionals often lack research experience and confidence, as previously discussed.

Keyser et al. (2008) describe the roles and responsibilities of the mentor and protégé in the research mentoring relationship. The authors suggest that the role of the mentor is to support the protégé's personal and professional development through strengthening their academic competency, their knowledge of and adherence to responsible conduct of research and by providing support and encouragement. In contrast, as with traditional mentoring relationships, the role of the protégé is to commit to the relationship and take personal ownership for the quality of the relationship. Over and above the benefits of mentoring described above, the research mentoring relationship has been found to help protégés develop strong professional networks, prepare manuscripts for submission for review and publication, apply for research grants and participate in professional research-related meetings (Keyser et al., 2008). 
The positive effects of research mentoring may work, at least in part, through increased self-efficacy of the protégé. Research self-efficacy refers to beliefs about one's ability to carry out and complete the tasks associated with conducting research (Bishop and Bieschke, 1998, as cited in Love, Bahner, Jones and Nilsson, 2007). Love, Bahner, Jones and Nilsson (2007) report that gaining experience in conducting research is a vital aspect of the development of research self-efficacy. The authors' survey data indicated that faculty support and mentoring were the most important contributors to satisfactory individual research experiences (Love, Bahner, Jones and Nilsson, 2007). Thus, being exposed to a supportive research mentoring environment and having the opportunity to learn from a mentor appears to increase an individual's positive beliefs regarding the ability to carry out research, which in turn should increase the total research commitment and output.

In the LIS spectrum, the benefits of mentoring have predominantly been explored with regards to career development, career transitioning and succession planning in light of the changing face of the library workforce (e.g., Freedman, 2009; Mosley, 2005; Murphy, 2008). Although Farmer, Stockham and Trussell (2009) reported that both LIS mentors and protégés listed positive research-related outcomes of their mentoring relationship, including presentations at conferences, conducting research and publishing, there is little published information regarding research mentoring in the LIS profession. Such information would add value to the LIS industry, as research skills and methods have been identified as an increasingly important part of the LIS profession (for example, Thorpe, Partridge and Edwards, 2008). This paper aims to contribute in this regard, by describing a formal LIS research-mentoring programme, from inception to evaluation.

\section{The project}

\subsection{Project aim and objectives}

The project was funded by the International Federation of Library Associations and Institutions (IFLA) and administered by the Library Theory and Research (LTR) Section. The two-year project aimed to encourage and support the development of research skills in the library profession, with a particular focus on new professionals. The specific objectives were to:

1. establish a formal research-mentoring programme;

2. develop practical strategies and recommendations on how to develop an ongoing sustainable research programme.

\subsection{The mentoring programme}

Planning of the programme commenced in February 2010 with a call for applications made in June. Twenty-two applications (including a CV, personal statement, and research topic outline) were received and reviewed by the project team. Six new LIS professionals within their first seven years of professional practice took part in the mentoring programme. Each new professional was 
partnered with an experienced library researcher or professional who provided mentoring and support. Together the protégés and mentors represented eight of the world's countries, Canada, Fiji, Germany, Italy, Jamaica, Nigeria, United States of America, and Trinidad and Tobago. In allocating mentors the following criteria were used, aiming to ensure that the mentor was:

1. located geographically close to the protégé (e.g. same city, same state or same country);

2. an experienced researcher in the topic and / or method that the protégé was interested in exploring;

3. interested, committed and available to take part in the full life of the mentoring programme.

No mentors had a previous relationship with the protégé to which they were partnered. To avoid any conflict of interest and to ensure a safe and open learning environment mentors and protégés were not based at the same institution (e.g. colleagues working together).

The protégés and mentors participated in a twelve-month mentoring programme from October 2010 to September 2011. During the programme each protégé was required to design and undertake a small research project in an area of interest to them. The mentor and protégé were introduced virtually (i.e. via email) and were encouraged to meet with each other (e.g. either in person or online using a tool such as Skype). At the commencement of the mentoring partnership, the protégé and mentor were required to compile and submit a mentoring agreement which outlined the agreed goals and objectives for the life of the partnership as well as strategies for communicating and dealing with problems that arise. The protégé also was encouraged to keep a learning journal during the project, a template for this was provided (Appendix A in the Supplementary File). It was originally intended that all 12 mentors and protégés would take part in a monthly online meeting (e.g. via technology such as Skype). The meetings would provide a vehicle to build a community of practice for all those taking part in the programme. Unfortunately the meetings could not be conducted as planned because of issues with technology, the busy schedules of the mentors and protégés, and challenges with locating a suitable time in light of the different time zones. However, during the programme regular contact with the mentors and protégés was made via email. This contact ensured those involved in the programme had someone to approach for support and / or advice. It also helped to keep the programme on track with reminders regarding due dates for milestones and other activities.

The protégé was required to submit two deliverables during the mentoring programme; a research proposal (see Appendix B) due approximately three months after commencing and a final report (see Appendix C) due at the end of the programme. A template for both deliverables was provided. The research proposal was peer reviewed by one international expert, and the project 
supervisory team reviewed the final report. In both cases feedback was provided to the protégé. All documentation used during the project is available upon request. A Moodle site was used to provide access to all the templates and other key resources relevant to building a successful mentoring relationship and in designing and undertaking a research study (e.g. recommended readings, how to guides). The site was dynamic; a basic site was established at the commencement of the programme with developments made progressively during the life of the programme. All mentors and protégés were encouraged to add to the site and / or to identify content they would like sourced and included into the site. The mentors and protégés were notified (via email) and encouraged to engage when new content was added to the site.

The mentoring programme was designed to recognise the individual needs of the six protégés, with each progressing well in light of their own circumstances. Four protégés completed their projects producing final reports, one protégé completed her project but did not submit a final report and one protégé completed her research proposal. The protégés each received a certificate of participation. The two best research projects, in the judgement of the project supervisor team, were invited to present their research results at the $78^{\text {th }}$ IFLA General Conference and Assembly in Helsinki, Finland. Links to these two papers (Chiessi, 2012, and Nilsen, 2012) can be found in this paper's list of references.

\subsection{Project evaluation}

Evaluation of the programme took place from October to December 2011. All protégés and mentors were invited to provide feedback on the mentoring programme via an online questionnaire (see Appendix D). A total of 6 (3 mentors, 3 protégés) completed the questionnaire, providing a response rate of $50 \%$. A brief summary of the key results follows.

Most of the respondents (4) had been involved in a mentoring programme in the past. The reasons respondents gave for participating in the Partnership could generally either be classified as Learning; to have practical experience of the research process ( 3 responses) or Teaching; to assist the profession by providing expertise to new researchers ( 3 responses), in line with what would be expected to be the driving forces behind being a protégé and mentor, respectively.

The hopes and expectations individuals reported in participating in the Partnership all seemed in line with the programme's goals:

To see and accompany a practical trial of an impact survey.

To publish the research I carried out and have a working relationship with my Mentor.

I had hoped to learn, make friends and gain insight to research and to actually publish my research. 
I was hoping to help someone develop their research skills and advance their career.

To benefit from the experience and guidance of my mentor in order to learn how to deal with my research topic and how to deal with research in general.

To offer guidance where it was needed.

However, only $50 \%$ of respondents reported that their expectations in participating in the programme had been met. Qualitative comments from respondents indicated that at least 2 of the 3 individuals who did not report that their expectations had been met did so because their research had not yet been published. Perhaps more support related to publishing research could be provided in future - this was one aspect of the research cycle that was largely left untouched by the programme support staff.

E-mail was the most frequent form of contact between mentors and protégés (4 responses), while in-person meetings were the most common form of contact for the remaining 2 respondents. Mentors met with their protégés monthly (84\%) or several times a month (16\%) and qualitative responses from survey participants indicated that the frequency of meetings varied depending on the stage of the project and their respective availabilities, as would be expected. However, the amount of contact may not have been enough: although 50\% of respondents indicated that the contact was "just right", 50\% reported that they would have preferred more contact.

Feedback about the Moodle site was mixed. Four participants reported that they visited the site and 2 of these participants reported that they found the site "helpful" while 2 reported that they found the site "neither helpful nor unhelpful". This indicates that there may be some room for growth with providing a support network for future participants. This was confirmed by comments from participants.

Only 2 of the 6 respondents reported that they agreed or strongly agreed with the statement "my expectations of my mentor/mentee were met" (3 neither agreed nor disagreed and 1 respondent disagreed). The expectations reported by participants included: "that she would find her own way in this very new and rather difficult topic", "I expected him to guide me all through my study", "That they would provide me with cues about how much guidance was needed and on what specific aspects of the project they most needed assistance". More clearly outlining the expectations of the mentors and protégés at the outset of the project may have been useful, as it is unclear whether both parties were aware of the expectations that their mentor/protégé had of them. Although the Moodle site included resources and readings about mentoring, 3 participants indicated that they would have appreciated more guidance on the mentor-protégé relationship. Perhaps some additional or more practical information would have been useful, such as a mentoring contract where mentors and protégés formally agree on goals and expectations. 
Although the Moodle site provided space for mentors and protégés to share ideas (private and public discussion forums) 2 respondents indicated that they would have liked a space such as this. This suggests that either participants were not aware of the Moodle website or that the spaces provided were not suitable to their needs. As one respondent writes:

I think that having 6 persons from 5 different parts of the world was a great opportunity: different research topics, different experiences (in life and profession). But I know almost nothing about the others and about their projects, and I think it was a lost occasion. Obviously every one of us was very busy with their everyday life and job AND the research, but maybe it would have been possible to share a little more of our experiences. Perhaps the sharing should be "run from above", by someone in charge of the partnership.

The Moodle spaces were largely left to the participants to use as they saw fit. For example, everyone was invited to introduce themselves and share time management / organisational tools and tips but only a few participants took this opportunity. Perhaps in the future the sharing needs to be more organised, for example reminder e-mails that include a small bio of each participant and a small blurb about the research project.

All mentors and protégés agreed that the Partnership was either "effective" or "very effective" in assisting protégés to develop research skills. One mentor commented, "the project focused the mentee to think deeply about research and to ask questions". The most rewarding part of the Partnership seemed to come from the research process itself:

I welcomed the chance to encourage someone who wanted to do research in the field.

I was (and still am) really interested in my research's topic and somehow I made the research I wanted to read.

[the most rewarding part of participating in the programme was] when I concluded my research work.

Thus, it seems clear that the Partnership brought the importance of conducting research to the forefront of the participant's minds.

Most pleasingly, $100 \%$ of participants reported that they would be involved in a research-mentoring programme again and all respondents indicated that they would recommend the IFLA Researcher-Librarian Partnership to other potential mentors and protégés.

\section{Recommendations}

In conclusion, a number of recommendations on the role of and process for delivering research mentoring programmes are offered. 
Recommendation 1: Based on the feedback from participants, it is suggested that the IFLA Researcher-Librarian Partnership should be offered again in the future.

Recommendation 2: It is suggested that the Moodle site be retained but additional support resources be added and the site be appropriately publicised, to ensure all participants are aware of the resources available. Particular emphasis should be placed on the mentor-protégé relationship (for example, adding practical guidance such as a goal setting template) and information about how to publish research.

Recommendation 3: To foster a meaningful and productive mentoring relationship regular communication and engagement between the mentor and protégé throughout the life of the programme should be encouraged and supported. For example, an online orientation at the commencement of the programme would allow participants to meet and to establish a rapport; and during the life of the project participants should make use of technologies such as Twitter, Skype and Instant Messaging to nurture an active relationship.

Recommendation 4: To ensure overall quality and sustainability of the programme suitable resourcing must be provided (e.g. a project officer responsible for developing and maintaining the Moodle site, for fostering a collegial environment).

\section{Discussion and Conclusions}

This paper has provided an overview of a research mentoring programme initiated by the International Federation of Library and Information Associations and Institutions (IFLA). The Researcher Librarian Partnership demonstrates how LIS practitioners, educators and professional associations can work together to support the development of research skills and knowledge in the profession.

The Partnership was a one-time two-year initiative that was undertaken to explore what was possible, and to consider how mentoring could play a part in building a culture of research in the LIS profession. The programme reveals how mentoring can help foster a research culture. Though this programme current LIS practitioners had the opportunity to develop their "experience" (Koufogiannakis and Crumley, 2006) with research. The programme provided a supportive and non-threatening environment in which the protégés could develop their skill, knowledge and confidence. By learning how to critically engage with, and conduct research, LIS practitioners will be better able to serve the individuals and communities they support.

The program came to a close at the end of 2011. Since this time a significant number of LIS professionals have contacted the association wanting to know if the programme would be offered again. Clearly there is both interest and a need for research mentoring in the LIS profession. The challenge is to find a way to continue this type of initiative in a sustainable and meaningful way.

One option which could be considered is to enlist publishers of LIS research to provide support for an annual research mentoring programme modelled on the 
IFLA LTR Section's project. Through this annual programme aspiring researchers would be invited to submit proposals to the LTR by a specified date each year, with volunteer members of the Section acting as reviewers of the projects and putting out a call for researchers from the IFLA LTR membership. In addition, the members of national and regional associations with LIS research interests could volunteer to work with the aspiring researchers on the project proposals selected as the most viable. This effort might be supported by a rotating group of LIS research publishers and research organisations coordinated by the IFLA LTR Section. It is hoped that the success of the project described in the paper would stimulate volunteers to step forward.

In terms of practical implications this project has shown that there is a need for mentoring of early career LIS professionals. The project has also shown one way that this need can be met. It now is up to the LIS profession to accept the responsibility to ensure that the mentoring process of early LIS career professionals be continued. It is suggested that international and national professional groups such as IFLA, the iSchools Caucus and the various national and regional LIS and information-orientated education programmes should be encouraged to participate in the future planning of a programme to mentor LIS and information researchers.

\section{References}

Berg, S. A., Jacobs, H. and Cornwell, D. (2013) Academic Librarians and Research: A Study of Canadian Library Administrator Perspectives. College and Research Libraries, 74 (6), 560-572.

Bettmann, M. (2009) Choosing a research project and a research mentor. Circulation: Journal of the American Heart Association, (119), 1832-1835.

Blixen, C. E., Papp, K. K., Hull, A. L., Rudick, R. A. and Bramstedt, K. A. (2007) Developing a mentorship program for clinical researchers. Journal of Continuing Education in the Health Professions, 27(2), 86-93.

Chiessi, S. (2012) Assessing the impact of Italian public libraries [online]. Paper presented at $78^{\text {th }}$ IFLA General Conference and Assembly, Session 105. URL: http://conference.ifla.org/past/2012/105-chiessi-en.pdf [accessed 8.11.14].

Connaway, L.S. (2014) Why Libraries? A call for user-centered assessment. BiD: Textos universitaris de biblioteconomia i documentacio, (32) [online]. URL: http://bid.ub.edu/en/32/connaway3.htm [accessed 8.11.14].

Eby, L. T., Allen, T. D., Evans, S. C., Ng, T. and DuBois, D. L. (2008) Does mentoring matter? A multidisciplinary meta-analysis comparing mentored and non-mentored individuals. Journal of Vocational Behavior, (72), 254-267. 
Farmer, D., Stockham, M. and Trussell, A. (2009) Revitalizing a mentoring program for academic librarians. College and Research Libraries, 70(1), 8-25.

Freedman, S. (2009). Effective mentoring. IFLA Journal, 35(2), 171-182.

Gibb, S. (1999). The usefulness of theory: A case study in evaluating formal mentoring schemes. Human Relations, 52(8), 1055-1075.

Hallam, G. and Newton-Smith, C. (2006). Evaluation of transitional mentoring for new library and information professionals: What are the professional and personal outcomes for the participants? Library Management, 27(3), 154-167.

Hallam, G. and Partridge, H. (2006) Evidence based library and information professionals: Whose responsibility is it anyway? Evidence Based Library and Information Practice [online], 1(3), 88-94. URL:

https://ejournals.library.ualberta.ca/index.php/EBLIP/article/viewFile/107/145 [accessed 8.11.14].

Harvey, R. (2002) Introduction. In: Williamson, K. (ed.) Research methods for students, academics and professionals: Information management and systems. 2nd ed. Centre for Information Studies, Charles Sturt University: Wagga Wagga. xiii-xvii.

Holmes, D. R., Hodgson, P. K., Simari, R. D. and Nishimura, R. A. (2010) Mentoring: Making the transition from mentee to mentor. Circulation: Journal of the American Heart Association, (121), 336-340.

Juznic, P. and Urbanija, J. (2003) Developing research skills in library and information studies. Library Management, 24(6/7), 324-31.

Keyser, D. J., Lakoski, J. M., Lara-Cinisomo, S., Schultz, D. J., Williams, V. L., Zellers, D. F. and Pincus, H. A. (2008) Advancing institutional efforts to support research mentorship: A conceptual framework and self-assessment tool. Academic Medicine, 83(3), 217-225.

Kostovich, C., Saban, K. and Collins, E. (2010) Becoming a nurse researcher: The importance of mentorship. Nursing Science Quarterly, 23(4), 281-286.

Koufogiannakis, D. and Crumley, E. (2006) Research in librarianship: Issues to consider. Library Hi Tech, 24(3), 324-240.

Kram, K. E. (1985) Mentoring at work: Developmental relationships in organizational life. Glenview: Scott Foresman.

Love, K., M., Bahner, A. D., Jones, L. N. and Nilsson, J. E. (2007) An investigation of early research experience and research self-efficacy. Professional Psychology: Research and Practice, 38(3), 314-320. 
Lumpkin, A. (2011) A model for mentoring university faculty. The Educational Forum, 75(4), 357-368.

Lumpkin, A. (2009) Follow the yellow brick road to a successful professional career in higher education. The Educational Forum, 73(3), 200-214.

McNicol, S. and Nankivell, C. (2001) The LIS research landscape: a review and prognosis [online]. Center for Information Research. URL:

http://www.researchgate.net/publication/228392587 The LIS research landscap

e_a_review_and_prognosis/links/00b4953c69e3058109000000/images/3.png [accessed 8.11.14].

Mosley, P. A. (2005) Mentoring gen x managers: Tomorrow's library leadership is already here. Library Administration and Management, 19(4), 185-192.

Murphy, S. A. (2008) Developmental relationships in the dynamic library environment: Re-conceptualizing mentoring for the future. The Journal of Academic Librarianship, 34(5), 434-437.

Nilsen, C. (2012) Faculty perceptions of librarian-led information literacy instruction in postsecondary education [online]. Paper presented at $78^{\text {th }}$ IFLA General Conference and Assembly, Session 105. URL:

http://conference.ifla.org/past/2012/105-nilsen-en.pdf [accessed 8.11.14].

Powell, R., Baker, L. and Mika, J. (2002) Library and information science practitioners and research, Library and Information Science Research, 24(1), 4972.

Thorpe, C., Partridge, H. and Edwards, S. L. (2008) Are library and information professionals ready for evidence based practice? [online]. Paper presented at ALIA Biennial Conference: Dreaming 08, Australian Library and Information Association (ALIA), Alice Springs. URL: http://eprints.qut.edu.au/28370 [accessed 8.11.14].

\section{Acknowledgement}

The authors would like to thank the members of the international library and information science profession who kindly contributed to this project as mentor or critical friend. The work was funded by the International Federation of Library and Information Associations. 


\section{Open access and copyright}

Library and Information Research is an open access journal. A freely available copy of this paper may be downloaded from the journal's website:

http://www.lirgjournal.org.uk

Copyright and associated moral rights in works published in Library and Information Research are retained by the author(s) but this paper may be used freely, with proper attribution, in educational and other non-commercial settings. 